\title{
Exploring the Use of Online Marketing Strategies and Digital Media to Improve the Brand Loyalty and Customer Retention
}

\author{
Mohammed T. Nuseir ${ }^{1}$ \\ ${ }^{1}$ Department of Management, Faculty of Business and Finances, The World Islamic Science \& Education \\ University, Jordan \\ Correspondence: Mohammed T. Nuseir, Department of Management, Faculty of Business and Finances, The \\ World Islamic Science \& Education University, Amman, Jordan. E-mail: drmnuseir@yahoo.com
}

Received: January 4, 2016

doi:10.5539/ijbm.v11n4p228

\author{
Accepted: January 11, 2016 \\ Online Published: March 15, 2016 \\ URL: http://dx.doi.org/10.5539/ijbm.v11n4p228
}

\begin{abstract}
As a marketing tool, internet and digital media is a significant strategic weapon which goes beyond borders and targets the specific audience in accordance to the consumer needs. It is not dependent on the location, area or region and free of all the temporal restrictions. This study focused on identifying the impact of the online internet and digital media marketing strategies in creating the brand loyalty and retaining the existing and new customers. This research was to explore the depth of internet and figure out the possible outcomes and benefits of using internet and digital media as a marketing tool. The study opted a primary quantitative method and conducted a survey of 200 consumers and results affirmed that internet is useful marketing tool which helps and assist the companies to target specific and their targeted audience to promote their brand or product and also retain their new and existing consumers. The study has finally revealed that internet marketing and digital media marketing facilitates the companies and brands to increase their popularity and make loyal customers.
\end{abstract}

Keywords: online marketing, marketing strategies, internet marketing, digital media, brand loyalty, customer retention, consumer perception

\section{Introduction}

The Internet has become a key, or one could say a strategic weapon: this is significant given the current hyper-competitive environment, which simultaneously raises the question of its reliability (Chen, 2006). Over the past twenty years, the development of information technology and a knowledge economy have made customer loyalty in the hotel industry a central issue for marketing scholars. By efficiently handling customer profiles through customer equity management, companies could maximize the lifetime value of each customer as one of their assets (Tsekouropoulos et al., 2013). Numerous scholars have used a variety of formulas to prove the value of customers' lifetime patronage to a company (Doostar \& Mohammadi, 2014). What seems to be lacking in customer equity theory, however, is an understanding of the strategies that cause customers to return to a business, a phenomenon known as customer loyalty, and which allows companies to maximize profits through repeat business.

The significance of online marketing is currently increasing, as we can observe changes in the ways people communicate and also in the ways they spend their free time. The advantage of the Internet as a communication medium likewise lies in the fact that it allows us to target the conveyed information at a precisely specified audience segment (Roblek, 2015). These facts seem important from the perspective of their use in public relations activities not only in the business sphere, but also in academic environment. Dilts, Hauser, and Hausknecht (2006) states that public relations in an online environment are mainly about convincing the public to use this medium to make positive comments about the organisation's products or services. Unlike the off-line environment, the nature of the Internet provides a possibility to quickly connect without any geographical constraints groups of people who are interested in discussing the organisation and its parts. There is still no widespread agreement regarding online marketing strategies and other digital media have an effect on the brand loyalty or in the retention of the consumers.

\section{Research Aim}

The main aim of this study is to explore the use of Online Marketing Strategies and Digital Media to improve the 
Brand Loyalty and Customer Retention.

\section{Research Objectives}

The main objectives of this study are:

1. To explore the concept of online marketing and digital media.

2. To identify the benefits of using online marketing strategies and digital media.

3. To figure out the impact of online marketing strategies and digital media on the Brand Loyalty and Customer Retention.

\section{Research Questions}

1. What role does online marketing strategies and digital media play in businesses?

2. Do the online marketing strategies and digital media help in improving the customer loyalty and customer retention?

\section{Research Method}

This study has incorporated the primary quantitative research with the help of survey questionnaire. The questionnaire was developed by the researcher after reviewing the past studies on the selected variables and highlighting the key determinants of those variables. Sample of 200 consumers were selected for this study. Data gathered through these questionnaires has been analysed with the help of MS Excel and SPSS software.

\section{Review of Related Literature}

"The future of retail is the integration of Internet and digital

services with the retail network."

\section{-Charles Dunstone}

\subsection{Marketing Strategies and Models}

The consumer enters the market to satisfy his economic wants. The firm achieves its goals by providing consumer want-satisfaction through the implementation of marketing strategy. Marketing strategy must be employed by a firm operating in a heterogeneous market (Thrassou \& Vrontis, 2008). The firm faces various possible courses of action. Management must make decisions concerning these possibilities so as to attain the firm's objectives. Marketing strategy is defined to be this process of decision-making with regard to the marketing function of the firm, i.e., the planning and execution of activities which attract customers to the firm.

Marketing strategy consists of three elements: target market selection, marketing mix implementation, and strategy adjustments. The target market is considered to be the group of customers whose patronage is sought because of profit expectations (Drossos et al., 2011). The marketing mix is the particular combination of marketing variables which is employed to solicit the patronage of the target market. Adjustments or changes in components of the other two elements of the marketing strategy must be made to keep the strategy abreast of changing market conditions.

There are three main objectives in marketing (Yu, 2006). 1) to create awareness and ensure an intended audience understands the basic concept behind the idea and its relevance to them; 2) to reduce or remove barriers surrounding the idea so that a proposed action takes minimal effort; and 3) to develop and manage relationships with the intended audience. Marketing always focuses on the audience's perspective. A target audience is defined using a specific set of values and interests, including demographics, geographic segmentation, behaviors, political values, social status and other variables determined by the required context. An ideal target audience is made of decision makers and/or influencers, who will ultimately be in charge of fulfilling the call to action. To do this, marketing professionals bridge, amongst others, psychology, sociology and graphic design principles in order to create a clearly-defined message for the target audience (Pandey, 2012). The message precedes the call to action. The message is the information intended for the audience to know, built in a tone that appeals to their values. For example, messages of hope have in general more impact than messages of doom to inspire audiences to take action.

Given the recent changes in the business environment, sticking with existing model is unlikely to work. All organizations need to be more nimble and responsive, and it is vital that they are more reactive to ideas and input from customers than they have been in the past. All must be prepared to test out new ideas in their model of delivery, and not just for innovation's sake, but in order to survive (Pandey, 2012). It is important for organizations to be clear which model they are working to, rather than just assuming a model will emerge by 
putting disciplines of marketing, sales, and service to task. There's no point choosing a customer management model that does not work with the functional strategies, and disciplines in place, and not addressing the changes required to these.

\subsubsection{Internet Technology and Internet Marketing}

Internet technology is one of the most significant technologies of the 20th century (Zhang et al., 2015). The Web is an Internet application that has played an important role in modern marketing and retailing. The Internet has been highly influential in removing separations between IT and "the business". While it is important to understand the internet's role in retailing and retail marketing from a higher level (strategic point of view), it is also important to understand the impact of the internet on various retailing aspects. Studying the characteristics of new media technology provides a structured context to understand social effects and compare different media (Goi, 2009). Understanding the internet's impact and potential on major aspects of retailing can result in better marketing programs and sustainable marketing strategies. By 2008 the Internet was an "old hat" for the executives at the advertising agency. The agency used the Internet for much of its internal and external communication, and much like the rest of the world, was beginning to use the Internet for marketing opportunities. Specifically, the agency explored the social networks of Facebook and Twitter as marketing avenues for many of the brands it represented (Cader \& Al Tenaiji, 2013).

The last several years have seen a dramatic increase in the amount of time and money consumers spend online. A recent survey reports that consumers spend around $33 \%$ of their time online (Corley II, Jourdan, \& Ingram, 2013). As a consequence, the Internet has become an important channel that firms can use to reach out and connect to consumers which has led to the emergence of online advertising. Several forms of online advertising has evolved over the year, e.g. sponsored search, display advertising, email marketing, classifieds and more recently social network advertising, sponsored search and display advertising dominating the online marketing landscape (Roberts \& Zahay, 2012). Internet advertising has become a significant component of advertisers' marketing mix. Firms spent close to US \$ 35 Billion on online advertising in the year 2011 and this expense is expected to double in the next 5 years (Lin, Ming, \& Bin, 2011). The online advertising spend surpassed the amount spent on newspaper advertising in the year 2010 and is expected to surpass television advertising by the year 2016. The internet has had a big impact on how customers think and buy: Facebook has more than 500 million active users at the time of writing. Twitter has 500 million tweets per day, 600 per second, and there are 4 million LinkedIn users. LinkedIn has become the network of choice for business people worldwide and possibly the most relevant and updated business directory (Çiçek \& Eren-Erdogmus, 2013). The power of customer pressure has increased. Complaint and referral is becoming ever more powerful, enabled of course by these and other internet applications.

"The key to using the Internet to extend and build relationships is to view ownership of information differently-you need to bring customers inside your business to create information partnerships. " (Michael Dell)

\subsubsection{Digital Media}

Dozens of digital tools, most notably mobile devices, allow users and consumers (and marketing practitioners) to easily share information with others, anytime and anywhere. In practice, many online forums usually require participants to register and provide some identification. Their online commentary sections, however, often do not require any personal identification from contributors (Erdoğmuş \& Cicek, 2012). Consequently, in some cases, digital audiences may find it difficult to judge the credibility of the sender and the message.

One of the most important benefits of digital media is the ability to support feedback, interactivity, and response, a factor that provides vital information on customers and prospects that can be used to fine-tune communications (Erdoğmuş \& Cicek, 2012). This is a process known as intelligent direct marketing-marketing driven by response. To support the process, the following digital communications can be used:

- data capture applications;

- $\quad$ predictive forms and surveys;

- $\quad$ online evaluators;

- $\quad$ interactive sales presentations;

- relationship publishing;

- Intelligence-driven Web conferences.

With digital media, it's possible to improve the presentation of product information, replacing single static images with interactive models that allow users to manipulate the product just as they would in real life 
(Thaichon, Lobo, \& Mitsis, 2012). Using a product configurator, an interactive design device built into a Web site, customers can change the colour, size, components, or any other variable feature of a product.

Digital media are opening up ever more opportunities for online marketing, helping to make communication targeting more precise and increasing levels of feedback and interactivity. Digital media support a process known as "intelligent marketing," in which content is refined in line with campaign response and feedback (Salehi et al., 2012). This can help marketers make better use of their budgets and increase customer loyalty.

Digital media allow marketers to deliver more value to customers. For instance, they enable customers to receive personalized communications and special offers that are tailored to their individual preferences (Cader, \& $\mathrm{Al}$ Tenaiji, 2013). This is particularly important in complex business-to-business marketing with large groups of decision-makers and a long sales cycle.

\subsection{Customer Retention and Brand Loyalty}

A clear targeting strategy, value proposition, and customer retention is of paramount importance for all organisations. Some scholars also argued customer loyalty were difficult to measure, so the integrated approach, which included attitudinal and behavioural dimension of loyalty, was employed through variety combination (Erdoğmuş \& Cicek, 2012). Loyalty programs or relationship marketing should focus not only on repeat benefits, but also on attitudinal loyalty, emotional loyalty, imagination, social influence, and pleasure (Laroche, Habibi, \& Richard, 2013). Due to the difficulty of observing customers' loyalty and learning their viewpoints, the dimensions of true loyalty cannot be identified (Dawes, Meyer-Waarden, \& Driesener, 2015). In addition, it was difficult to identify what motivators or strategies attracted customer loyalty except the repurchase behaviours by experimental design. E-Commerce has also changed the balance of power. The role of digital marketing (DM) in a firm's marketing strategy has been expanding in the industrial sector, as evidenced by industrial firms' increasing investments in DM activities, which currently account for approximately one-quarter $(26 \%)$ of industrial firms' total marketing budgets (Ying \& Jin, 2014). In addition to cost effectiveness and changes in customer behavior, investments in DM are motivated by its results being more easily measured compared with those of traditional marketing (Dehkordi et al., 2012). As customers are increasingly interacting with companies through digital channels, marketers have realized the need to track these interactions and to measure their performance (Ying \& Jin, 2014). For this purpose, firms must adopt Web analytics (WA), defined as "the measurement, collection, analysis and reporting of Internet data for the purposes of understanding and optimizing Web usage" (Web Analytics Association, 2008, p. 3).

Contrary to the early image that the internet was a place for bargain hunting, the internet has become more frequently viewed as a place to provide better service and enhance consumer relationships (Thaichon, Lobo, \& Mitsis, 2012). It has been realized that companies must strive for a complete view of their customers, as the relationship shifts from commerce to collaboration (Cader \& Al Tenaiji, 2013). Due to its potential for interactive communication, the Internet has evolved into a promising tool for relationship marketing.

Customer satisfaction is driven more by quality and customization than by value (price) and reliability. Satisfaction can be transaction-specific or cumulative, and these have varying effects on consumer perceptions (Corley II, Jourdan, \& Ingram, 2013). While equity, or "a fairness, lightness, or deservingness comparison to other entities, whether real or imaginary, individual or collective, person or non-person" (Dawes, Meyer-Waarden, \& Driesener, 2015), is a driver of transaction-specific satisfaction, it is more of a post-satisfaction evaluation when modeling cumulative satisfaction. Satisfaction is highly correlated with long term relationships (Ying \& Jin, 2014). Dilts, Hauser, and Hausknecht (2006) have mentioned in their research that the satisfaction is widely used as a mediator to customer relationships. The role of satisfaction in the customer relationship building process also may vary according to the business context and consumer level variables. By contrast, trust has been conceptualized as a link between buyer-seller relationships and customer retention and loyalty (Thrassou \& Vrontis, 2008). Trust refers to consumer willingness to rely on an exchange partner in whom one has confidence, and it can be a multifaceted construct (Dawes, Meyer-Waarden, \& Driesener, 2015). For example, consumers may have different trust in a product, a company, or a sales person. Trust can be transformed to value and customer loyalty.

The marketing opportunities fuelled by the internet can be viewed from three aspects (Corley II, Jourdan, \& Ingram, 2013): enhanced selling process, enhanced customer buying experience, and enhanced customer usage experience. The selling process can be improved by customer input, customer targeting, customer aggregation, benefit selling, and achievement selling. The customer buying experience can be enhanced by providing solutions and tailored products, while the customer usage experience can be enhanced with value-added services and customized support. 


\section{Findings and Results}

Table 1. Sample characteristics

\begin{tabular}{llllll}
\hline Gender & \multicolumn{5}{l}{} \\
\hline \multirow{2}{*}{ Valid } & Male & Frequency & Percent & Valid Percent & Cumulative Percent \\
& Female & 52 & 74.0 & 74.0 & 74.0 \\
& Total & 200 & 26.0 & 26.0 & 100.0 \\
& & 100.0 & 100.0 & \\
\hline
\end{tabular}

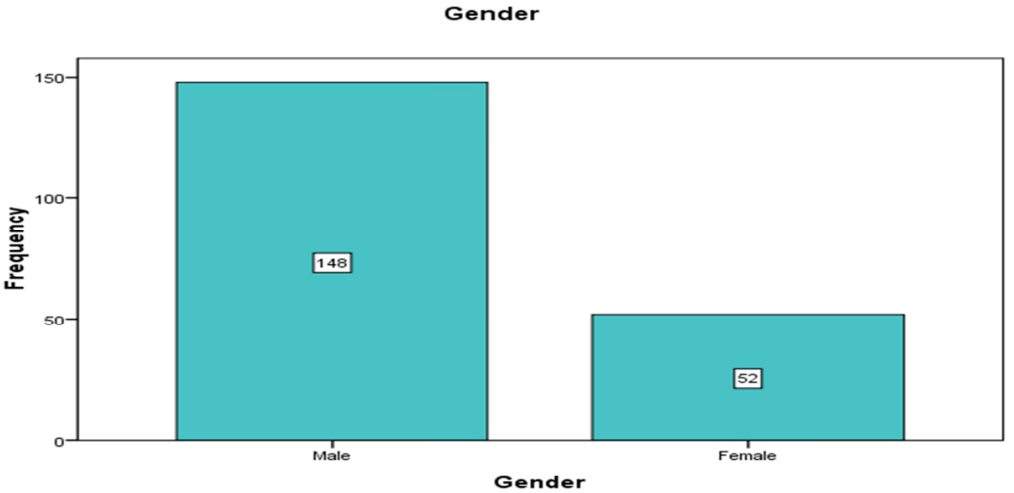

The above table displays that from the total of 200 respondents 148 were male respondents and 52 were female respondents. These male respondents concluded $74 \%$ of the population whereas female respondents concluded $26 \%$ of the population.

\begin{tabular}{lllll}
\hline \multirow{2}{*}{ Factors } & \multicolumn{2}{l}{ Gender } & \\
\cline { 3 - 4 } & & Male & Female & Total \\
\hline Age & $18-25$ years & 15 & 5 & 20 \\
& $26-30$ years & 27 & 7 & 34 \\
& $31-35$ years & 32 & 12 & 44 \\
& $36-40$ years & 62 & 23 & 85 \\
& Over 40 years & 12 & 5 & 17 \\
Occupational Status & Student & 13 & 7 & 20 \\
& Private Employee & 38 & 17 & 55 \\
& Government Employee & 37 & 11 & 48 \\
& Retired/Housewife & 45 & 14 & 59 \\
& None of the above & 15 & 3 & 18 \\
& Single & 47 & 16 & 63 \\
Marital Status & Married & 52 & 21 & 73 \\
& Divorcee & 31 & 8 & 39 \\
& Widowhood & 18 & 7 & 25 \\
\hline
\end{tabular}




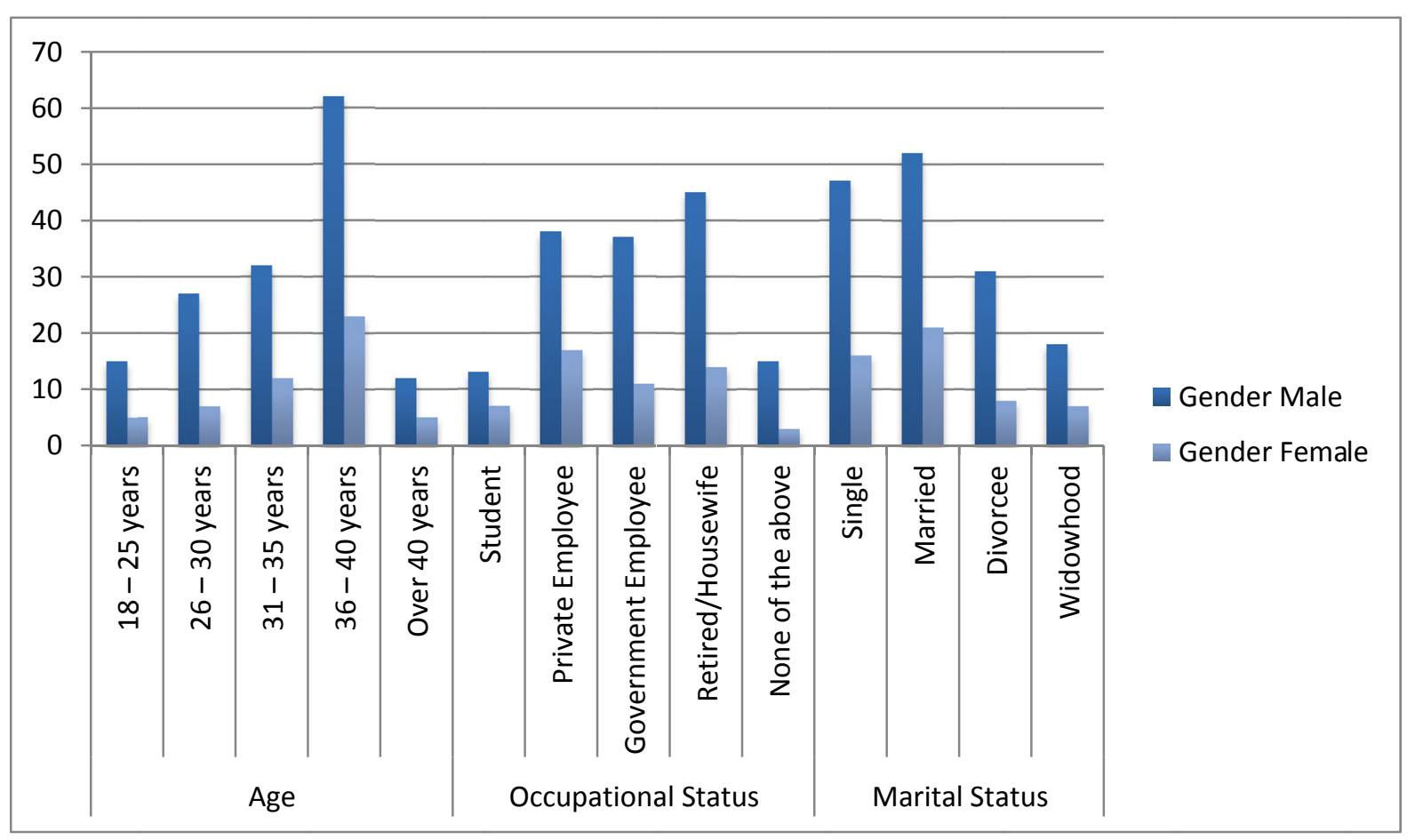

The above table represents the three demographic characteristics of the respondents of the survey. The age factor shows that the majority of the participants were of the age group of 36-40 years i.e. around 85 respondents (62 male respondents and 23 female respondents).

Occupational status of the respondents showed that the majority of the participants belong to retired/housewife group which concluded of 45 males and 14 female respondents.

Marital status of the participants showed that majority of the respondents was married according to the conducted survey. From the total of 73 married respondents 52 were male respondents and 21 were female respondents.

\subsection{Survey Results}

Table 2. Has the internet marketing ever influenced and made you to purchase any product?

\begin{tabular}{llllll}
\hline & & Frequency & Percent & Valid Percent & Cumulative Percent \\
\hline Valid & Yes & 150 & 75.0 & 75.0 & 75.0 \\
& No & 50 & 25.0 & 25.0 & 100.0 \\
& Total & 200 & 100.0 & 100.0 & \\
\hline
\end{tabular}

The above table illustrates that 150 participants has agreed to get influenced and 50 participants denies to be influenced by the internet marketing. According to the results, it becomes visible that $75 \%$ of the respondents agree that internet marketing helps in influencing their purchasing decision.

Table 3. Do you use internet for the purpose of product information?

\begin{tabular}{llllll}
\hline & & Frequency & Percent & Valid Percent & Cumulative Percent \\
\hline Valid & Yes & 152 & 76.0 & 76.0 & 76.0 \\
& No & 48 & 24.0 & 24.0 & 100.0 \\
& Total & 200 & 100.0 & 100.0 & \\
\hline
\end{tabular}

The above chart demonstrates that out of 200 respondents, 152 participants has agreed to use internet for the product information and 48 participants denies to use the internet for getting product information. According to the results, it becomes clear that $76 \%$ of the participants have agreed that they use internet for the purpose of product information. 
Table 4. Do you use internet for the shortlisting of the products you want to purchase?

\begin{tabular}{llllll}
\hline & & Frequency & Percent & Valid Percent & Cumulative Percent \\
\hline Valid & Yes & 151 & 75.5 & 75.5 & 75.5 \\
& No & 49 & 24.5 & 24.5 & 100.0 \\
& Total & 200 & 100.0 & 100.0 & \\
\hline
\end{tabular}

The table box displays that out of 200 participants 49 participants denied that they never use internet for shortlisting of products whereas 151 participants agreed that they use internet for shortlisting their products for purchasing. From the above chart, it becomes significant that $75.5 \%$ of the participants use internet for shortlisting their products for purchasing.

Table 5. Have you ever come across any marketing campaign or advertising of any particular product or company online?

\begin{tabular}{llllll}
\hline & & Frequency & Percent & Valid Percent & Cumulative Percent \\
\hline Valid & Yes & 148 & 74.0 & 74.0 & 74.0 \\
& No & 52 & 26.0 & 26.0 & 100.0 \\
& Total & 200 & 100.0 & 100.0 & \\
\hline
\end{tabular}

The above table demonstrates that 148 participants have agreed that they have seen many online advertising campaigns whereas 52 participants have never come across such advertising campaigns. According to the results, it becomes visible that $74 \%$ of the participants agreed that they usually come across such marketing campaigns.

Table 6. Do you think companies using the online medium for promoting or marketing their product benefit them?

\begin{tabular}{llllll}
\hline & & Frequency & Percent & Valid Percent & Cumulative Percent \\
\hline Valid & Yes & 140 & 70.0 & 70.0 & 70.0 \\
& No & 60 & 30.0 & 30.0 & 100.0 \\
& Total & 200 & 100.0 & 100.0 & \\
\hline
\end{tabular}

From the illustrative chart it becomes clear that $70 \%$ of the participants had used online medium for promoting or marketing their product where as $30 \%$ of the participants have disagreed to use online medium for promoting their products.

Table 7. What do you think is the highest benefit of using online internet marketing strategy?

\begin{tabular}{llllll}
\hline & & Frequency & Percent & Valid Percent & Cumulative Percent \\
\hline Valid & Web Experience personalization & 59 & 29.5 & 29.5 & 29.5 \\
& Competitor Analysis & 86 & 43.0 & 43.0 & 72.5 \\
& Cost Reduction & 36 & 18.0 & 18.0 & 90.5 \\
& Others & 19 & 9.5 & 9.5 & 100.0 \\
& Total & 200 & 100.0 & 100.0 & \\
\hline
\end{tabular}

According to the survey conducted, the above mentioned results clearly displays that 86 out of 200 participants has mentioned competitor analysis as the major benefit of using internet marketing strategy and 36 participants mentioned it for cost reduction. 
Table 8. Has any of the products you purchased online has made you repurchase that product again?

\begin{tabular}{llllll}
\hline & & Frequency & Percent & Valid Percent & Cumulative Percent \\
\hline Valid & Yes & 150 & 75.0 & 75.0 & 75.0 \\
& No & 50 & 25.0 & 25.0 & 100.0 \\
& Total & 200 & 100.0 & 100.0 & \\
\hline
\end{tabular}

The above chart demonstrates that out of 200 respondents 150 participants has agreed to repurchase the products again and 50 participants denied repurchasing the products. According to the results, it becomes clear that $75 \%$ of the participants have agreed to repurchase the products again.

Table 9. Do you purchase the online marketed products?

\begin{tabular}{llllll}
\hline & Frequency & Percent & Valid Percent & Cumulative Percent \\
\hline \multirow{3}{*}{ Valid } & Quiet Rarely & 63 & 31.5 & 31.5 & 31.5 \\
& Quiet Often & 80 & 40.0 & 40.0 & 71.5 \\
& Very Often & 37 & 18.5 & 18.5 & 90.0 \\
& Frequently & 20 & 10.0 & 10.0 & 100.0 \\
& Total & 200 & 100.0 & 100.0 & \\
\hline
\end{tabular}

The above chart represents that out of 200 respondents 80 participants said that they purchase online marketed products quite often and 63 participants said that they purchase it quite rarely. So, it is visible that $40 \%$ of the total participants purchase online marketed products.

Table 10. Do you think the internet marketed new products are reliable and satisfactory?

\begin{tabular}{llllll}
\hline & & Frequency & Percent & Valid Percent & Cumulative Percent \\
\hline \multirow{2}{*}{ Valid } & Yes & 143 & 71.5 & 71.5 & 71.5 \\
& No & 57 & 28.5 & 28.5 & 100.0 \\
& Total & 200 & 100.0 & 100.0 & \\
\hline
\end{tabular}

The results displays that 143 participants believe that the products purchased online are more reliable and satisfactory but 57 participants denied the fact. Out of $100 \%$ only $28.5 \%$ of the participants disagree with the statement whereas $71.5 \%$ agrees to the statement.

Table 11. Has any of the online marketed product which you have purchased has made you brand loyal?

\begin{tabular}{llllll}
\hline & & Frequency & Percent & Valid Percent & Cumulative Percent \\
\hline Valid & Yes & 146 & 73.0 & 73.0 & 73.0 \\
& No & 54 & 27.0 & 27.0 & 100.0 \\
& Total & 200 & 100.0 & 100.0 & \\
\hline
\end{tabular}

From the above illustrative chart it becomes clear that $73 \%$ of the participants said that they more loyal towards the brand when purchased online and $27 \%$ of the participants disagree to the fact. Out of 200 respondents 146 respondents had agreed that products which they had purchased online have made them brand loyal whereas 56 respondents disagreed to the statement. 
Table 12. Which of the following online marketing strategy do you think is most effective in influencing you to purchase a product?

\begin{tabular}{llllll}
\hline & Frequency & Percent & Valid Percent & Cumulative Percent \\
\hline Valid & Social Media Marketing & 27 & 13.5 & 13.5 & 13.5 \\
& Email Marketing & 35 & 17.5 & 17.5 & 31.0 \\
& Search Engine Optimization (SEO) & 52 & 26.0 & 26.0 & 57.0 \\
Blogs or Discussion Forums & 70 & 35.0 & 35.0 & 92.0 \\
& Others & 16 & 8.0 & 8.0 & 100.0 \\
Total & 200 & 100.0 & 100.0 & \\
\hline
\end{tabular}

According to the chart, it is vibrant that blog or discussion forums are most effective online marketing strategy as compared to others. $35 \%$ of the participants have voted for blogs and discussion forum whereas $13.5 \%$ of the participants have voted for social media marketing and $26 \%$ of the participants voted for search engine optimization.

\section{Discussion}

At the strategic level, the role of the internet in retailing has been discussed in terms of the role of the internet in marketing. As stated by Singh and Cullinane (2010), "the internet, a major component in this technological revolution, has progressed from an information-centric medium to one that is increasingly being characterized by the creation, dissemination and coordination of collective intelligence" (p. 202). The use of interactive media may not, itself, comprise a specific marketing technique since many marketing approaches can be implemented with or without IT/Internet infrastructure. For example, the idea of database marketing was widely used in direct marketing long before the existence of database technology (Tsekouropoulos et al., 2013). Thus, instead of viewing internet marketing as a category of marketing techniques, internet marketing can be viewed simply as electronic media-enabled marketing. Following Dilts, Hauser, and Hausknecht (2006), the internet's impact on consumer marketing can be viewed from a marketing tool or marketplace perspective. The first perspective considers the internet as one of many tools available for marketers to communicate and sell their products to customers (Drossos et al., 2011). The second view recognizes the potential power of the internet to create a new marketplace (Roberts \& Zahay, 2012).

A study by Thaichon, Lobo, and Mitsis (2012) has stated, "With the increased adoption ad fission of the Internet, World Wide Web is becoming gradually a standard advertisement platform. The Web is offering business advertisement world with more rich media tools, interactive services, and global reach. In an effort to explore the factors that affect online advertisement effectiveness, this paper investigate the factors that influence online advertisement and hence the purchasing intention among Jordanian university students. These findings can help business understand what matters more for a young country of consumer in a developing country context. Thus, business can develop more effective online advertisement campaigns".

The internet can have major impacts on a variety of retailing dimensions, and researchers have used various frameworks to discuss these impacts. For example, Agag and Elbeltagi (2014) discussed the internet's impact on retailing from globalization, human resources, consumer behavior, and retail formats. Agag and Elbeltagi (2014) have provided a framework to systematically view the internet's impact on the retail market. Roberts and Zahay (2012) categorized the unique characteristics of the internet for retail applications from three dimensions: technology infrastructure, channel integration, and market information. Market effects were analyzed through product offerings, a new consumer participation model, and changes in industrial structure. Others have focused on specific issues such as interactivity (Hamid \& McGrath, 2015), price searching (Mikians et al., 2012), and multi-channel distribution (Hsieh et al., 2012).

The Internet can be an interactive channel. Many applications, such as personalization and online communities (Thaichon, Lobo, \& Mitsis, 2012), can help to provide interactivity to consumers. Individual customers can receive tailored information through user profiles and identification. Consumers can be welcomed with a personalized greeting when entering a site. When a returning consumer visits a Website, the site can alter color, layout, and content according to the individual's pre-recorded preferences.

Online communities are another interactive online application. The Web provides a community-building infrastructure (chat rooms, bulletin boards, interactive events), which has a positive effect on loyalty intentions (Cader \& Al Tenaiji, 2013). Dialogue can proceed in real time in chat rooms, or asynchronously on bulletin boards. It was found that personalized web sites developed stronger consumer-brand relationships for respondents with 
extensive Internet experience, and customer communities developed stronger relationships among respondents with limited Internet experience (Thaichon, Lobo, \& Mitsis, 2012).

Online consumers have more opportunities for product or service involvement. Online consumers can even be involved in product design and product testing (Roblek, 2015). For example, online consumers can help to design cars or select new songs for promising artists. The internet enables them to provide product feedback much more easily than they could in the traditional market (Cader \& Al Tenaiji, 2013). They can search for answers to their problems and share knowledge in virtual communities. The value chain becomes transparent to them in the sense that they can understand what happens behind the retail scene; thus, online consumers may feel more involved in the value delivery process.

\section{Conclusion}

Marketing strategy adopted by the company reflects the three processes of the company which the marketing impacts. These processes are the product management or development, supply chain management and customer relationship management. This study has highlighted the impact of marketing on the customer relationship management, i.e. the impact of internet marketing and digital media marketing on the brand loyalty creation and retention of the consumers more precisely. In light of above findings and review of the related literature, it has been concluded that the people are influenced by the marketing strategies used by the companies based on the internet and digital media. The companies use the internet technology to market their product as this is an era of innovation and online technology and every single individual in this planet today uses the internet for various purposes. The companies focuses on the internet and digital media as effective marketing strategy because it is cost effective and also helps them in assisting to have the competitors analysis and check what their new products are and how rigorously are they marketing their brand or product. It was also seen that this online internet marketing have assisted the consumers in personalizing their requirements and needs so that companies could market only those products which consumers need. Web experience personalization helped the companies to understand the needs of the consumers and segment them and market them the products or brands in accordance to their needs, that is, this internet marketing strategies assist the companies to identify their target audience and market their product only to those audience. Individual customers can receive tailored information through user profiles and identification. This study showed that the majority of the respondents agreed that they are influence by the internet marketing of the products or brands which persuades them to purchase those brands or products. Also, the survey result showed that majority of the participants agreed that they purchased the online internet marketed product and as they liked that product so they repurchased that product again. This means that the internet marketing has helped the company to retain their customer and increased brand loyalty. The result showed the internet marketing has facilitated the companies and brands to progress further and increase the customer retention ratio.

\section{References}

Agag, G., \& Elbeltagi, I. (2014). E-retailing Ethics in Egypt and Its Effect on Customer Repurchase Intention. In ICT and Society (pp. 1-14). Berlin Heidelberg: Springer.

Cader, Y., \& Al Tenaiji, A. A. (2013). Social media marketing. International Journal of Social Entrepreneurship and Innovation, 2(6), 546-560. http://dx.doi.org/10.1504/IJSEI.2013.059955

Chen, C. Y. (2006). The comparison of structure differences between internet marketing and traditional marketing. International Journal of Management and Enterprise Development, 3(4), 397-417. http://dx.doi.org/10.1504/IJMED.2006.009088

Çiçek, M., \& Eren-Erdogmus, I. (2013). Social media marketing: Exploring the user typology in Turkey. International Journal of Technology Marketing, 8(3), 254-271.

Corley II, J. K., Jourdan, Z., \& Ingram, W. R. (2013). Internet marketing: A content analysis of the research. Electronic Markets, 23(3), 177-204. http://dx.doi.org/10.1007/s12525-012-0118-y

Dawes, J., Meyer-Waarden, L., \& Driesener, C. (2015). Has brand loyalty declined? A longitudinal analysis of repeat purchase behavior in the UK and the USA. Journal of Business Research, 68(2), 425-432. http://dx.doi.org/10.1016/j.jbusres.2014.06.006

Dehkordi, G. J., Rezvani, S., Salehi, M., Eghtebasi, S., \& HasanAbadi, A. (2012). A conceptual analysis of the key Success of business in terms of internet marketing. Interdisciplinary Journal of Contemporary Research in Business, 4(1), 811.

Dilts, J., Hauser, W. J., \& Hausknecht, D. (2006). A hybrid multichannel approach to internet marketing: Think globally, act locally. International Journal of Internet Marketing and Advertising, 3(2), 107-119. 
http://dx.doi.org/10.1504/IJIMA.2006.010294

Doostar, M., \& Mohammadi, M. H. (2014). Studying and prioritising the effective elements of internet advertising on e-marketing. International Journal of Services and Operations Management, 18(1), 57-73. http://dx.doi.org/10.1504/IJSOM.2014.060447

Drossos, D. A., Fouskas, K. G., Kokkinaki, F., \& Papakyriakopoulos, D. (2011). Advertising on the internet: perceptions of advertising agencies and marketing managers. International Journal of Internet Marketing and Advertising, 6(3), 244-264. http://dx.doi.org/10.1504/IJIMA.2011.038238

Erdoğmuş, İ. E., \& Cicek, M. (2012). The impact of social media marketing on brand loyalty. Procedia-Social and Behavioral Sciences, 58, 1353-1360.

Goi, C. L. (2009). Perception of internet users and marketers on internet marketing activities: Malaysia perspective. International Journal of Business Forecasting and Marketing Intelligence, 1(2), 181-199.

Hamid, N. R. A., \& McGrath, M. G. (2015). The diffusion of internet interactivity on retail web sites: A customer relationship model. Communications of the IIMA, 5(2), 4.

Hsieh, Y. C., Roan, J., Pant, A., Hsieh, J. K., Chen, W. Y., Lee, M., \& Chiu, H. C. (2012). All for one but does one strategy work for all? Building consumer loyalty in multi-channel distribution. Managing Service Quality: An International Journal, 22(3), 310-335.

Laroche, M., Habibi, M. R., \& Richard, M. O. (2013). To be or not to be in social media: How brand loyalty is affected by social media? International Journal of Information Management, 33(1), 76-82. http://dx.doi.org/10.1016/j.ijinfomgt.2012.07.003

Lin, B., Ming, S., \& Bin, H. (2011, May). Virtual brand community participation and the impact on brand loyalty: A conceptual model. In Business Management and Electronic Information (BMEI), 2011 International Conference (Vol. 1, pp. 489-492). IEEE.

Mikians, J., Gyarmati, L., Erramilli, V., \& Laoutaris, N. (2012, October). Detecting price and search discrimination on the internet. In Proceedings of the 11th ACM Workshop on Hot Topics in Networks (pp. 79-84). ACM. http://dx.doi.org/10.1145/2390231.2390245

Pandey, A. (2012). Optimising online marketing resources: SEO strategy. International Journal of Technology Marketing, 7(3), 267-277. http://dx.doi.org/10.1504/IJTMKT.2012.048126

Roberts, M., \& Zahay, D. (2012). Internet marketing: Integrating online and offline strategies. Cengage Learning.

Roblek, V. (2015). Impact of Internet and Social Media on Organizational Change of OTC Medicines Marketing Management. International Journal of Electronic Marketing and Retailing, 6(3), 239-258.

Salehi, M., Mirzaei, H., Aghaei, M., \& Abyari, M. (2012). Dissimilarity of E-marketing VS traditional marketing. International Journal of Academic Research in Business and Social Sciences, 2(1), 814-825.

Singh, T., \& Cullinane, J. (2010). Social networks and marketing: Potential and pitfalls. International Journal of Electronic Marketing and Retailing, 3(3), 202-220. http://dx.doi.org/10.1504/IJEMR.2010.034829

Thaichon, P., Lobo, A., \& Mitsis, A. (2012). Investigating the antecedents to loyalty of internet service providers in Thailand: developing a conceptual model. ANZMAC at Adelaide, Australia, 3-5.

Thrassou, A., \& Vrontis, D. (2008). Internet marketing by SMEs: towards enhanced competitiveness and internationalisation of professional services. International Journal of Internet Marketing and Advertising, 4(2-3), 241-261. http://dx.doi.org/10.1504/IJIMA.2008.017024

Tsekouropoulos, G., Andreopoulou, Z., Koliouska, C., \& Katsonis, N. (2013). Marketing and organisational evaluation of rural firms in the internet. International Journal of Technology Marketing, 8(3), 272-286. http://dx.doi.org/10.1504/IJTMKT.2013.055342

Web Analytics Association. (2008). Web analytics definitions. Digital Analytics Association.

Ying, H. U. A., \& Jin, C. H. E. N. (2014). Research on Effects of Internet Involvement on Customer Loyalty from Perspective of Customer Participation. International Business, 3, 10.

Yu, J. (2006). The evolution of Chinese consumers on the internet and its implications for marketing. International Journal of Electronic Marketing and Retailing, 1(1), 30-47.

Zhang, H., Zhang, K. Z., Lee, M. K., \& Feng, F. (2015). Brand loyalty in enterprise microblogs: Influence of 
community commitment, IT habit, and participation. Information Technology \& People, 28(2). http://dx.doi.org/10.1108/ITP-03-2014-0047

\section{Copyrights}

Copyright for this article is retained by the author(s), with first publication rights granted to the journal.

This is an open-access article distributed under the terms and conditions of the Creative Commons Attribution license (http://creativecommons.org/licenses/by/3.0/). 